\title{
Para una revisión de las tesis sobre el melodrama: amor maternal y anarquismo en La ley que olvidaron, de José Agustín Ferreyra (Argentina, 1937)
}

Mirta VARELA ${ }^{1}$

Resumen:

Si bien el melodrama es un género moderno que consiguió un lugar central en la industria cultural, no fue sino hasta la década de 1970 que la crítica inició un proceso que condujo a su legitimación cultural. En América Latina, las hipótesis sobre el rol del melodrama fundaron las bases de la historiografía de los medios del continente, de allí que se trate de un tema ineludible para este campo de estudios. El presente artículo propone revisar esas tesis y formular algunas preguntas que, según el análisis propuesto, quedaron obturadas desde los años 1980. Para conseguir ese propósito, analizaremos un film cuyo guión pertenece a José González Castillo, un autor anarquista que utilizó el melodrama y la popularidad de una actriz como Libertad Lamarque para reclamar la necesidad de legislar en torno a temas familiares como la adopción. Las conclusiones discuten el modo en que el melodrama - y la crítica que fue al "rescate" del género - habría conseguido legitimar el punto de vista del débil - el pobre, la mujer, el joven - mediante un mecanismo de inversión que produce efectos paradójicos.

Palabras clave:

Melodrama. Cine. Anarquismo. Adopción, Argentina.

\section{Revisiting the thesis on melodrama: maternal love and anarchism in $\mathrm{La}$ ley que olvidaron of José Agustín Ferreyra (Argentina, 1937)}

\begin{abstract}
:
Although Melodrama is a modern genre that reach a central position in the Cultural Industry, it was not until 1970's that the critique started a process leading to its cultural legitimation. In Latin America, the thesis on Melodrama set the basis of the historiography of Media History in the continent, therefore it is an unavoidable subject for this field. This article propose to revisit those thesis in order to pose some questions that, according to the analysis, are closed since the 1980's. For that purpose, we will analyse a film wich script belongs to José González Castillo, an anarchist author who used the melodrama and the popularity of an actress like Libertad Lamarque to claim the necessity of laws on family issues like adoption. The conclusions discuss the way in which melodrama - and also the critique wich "rescue" the genre - would have achieved to legitimate the point of view of the weak - the poor, the woman, the young - by means of a mecanism of inversion that produces paradoxical effects.
\end{abstract}

Keywords:

Melodrama. Cinema. Anarchism. Adoption. Argentina

\section{Para uma revisão das teses sobre o melodrama: amor materno e anarquismo em La ley que olvidaron, por José Agustín Ferreyra (Argentina, 1937)}

Resumo:

Embora o melodrama seja um gênero moderno que alcançou um lugar central na indústria cultural, foi apenas na década de 1970 que os críticos iniciaram um processo que levou a sua legitimação cultural. Na América Latina, as hipóteses sobre o papel do melodrama lançaram as bases da historiografia dos meios de

\footnotetext{
${ }^{1}$ Doctora por la Universidad de Buenos Aires, Investigadora del Consejo Nacional de Investigaciones Científicas y Técnicas de Argentina. E-mail: varelamirta@gmail.com
} 
comunicação do continente, sendo, portanto, um assunto inevitável para esse campo de estudos. Este artigo propõe revisar essas teses e formular algumas questões que, segundo a análise proposta, permaneceram fechadas desde a década de 1980. Para alcançar este objetivo, vamos analisar um filme cujo roteiro pertence a José González Castillo, um autor anarquista que usou o melodrama e a popularidade de uma atriz como Libertad Lamarque para reivindicar a necessidade de legislar em torno de temas familiares como a adoção. As conclusões discutem a maneira pela qual o melodrama - e a crítica que foi ao "resgate" do gênero - teria legitimado o ponto de vista do fraco - o pobre, a mulher, o jovem - por meio de um mecanismo de investimento que produz efeitos paradoxais.

Palavras-chave:

Melodrama. Cinema. Anarquismo. Adoção. Argentina.

\section{Introducción}

En 1937 se estrena La ley que olvidaron, un film protagonizado por Libertad Lamarque y dirigido por José Agustín Ferreyra que venía a ratificar la eficacia de una fórmula. En efecto, un año antes la productora de Alfredo Murúa (SIDE - Sociedad Impresora de Discos Electrofónicos) había conseguido la aprobación del público con otros dos films - Ayúdame a vivir y Besos Brujos - que combinaban melodrama, canciones populares y un estrellato en ascenso. Las historias del cine han leído esa trilogía como ejemplos acabados de las producciones que volvían competitivo el cine argentino en el mercado hispanohablante (COUSELO, 1969; DI NÚBILA, 1998). La ley que olvidaron introduce, además, un rasgo peculiar. Su guión pertenecía a José González Castillo, un prolífico autor de teatro que había incursionado con éxito en la industria cinematográfica. En 1915 había obtenido el primer gran suceso de la historia del cine argentino al utilizar fragmentos de poetas gauchescos para el subtitulado de Nobleza Gaucha. En 1919 había escrito asimismo el guión de Juan sin ropa, un film que la crítica valoró como un antecedente del cine político y social (LUSNICH; PIEDRAS, 2009) donde era posible reconocer la impronta anarquista de González Castillo (CUARTEROLO, 2009). Tanto las inclinaciones políticas del autor como la censura a Los invertidos - una pieza de 1914 que aborda el tema de la homosexualidad - atraparon la atención de historiadores y críticos. ¿Era González Castillo el guionista más apropiado para el film que protagonizaría Libertad Lamarque en un papel tan extremadamente angelical que fue definido como el de una “madre virgen” (COSSE, 2006)? ¿En qué medida es La ley que olvidaron un melodrama representativo de la industria cultural de la década de 1930?

Desde los años sesenta, el melodrama fue revisitado con gesto vanguardista por algunos autores. Después de un periodo en que parecía agotado, la industria cultural hizo renacer el género para nuevos públicos y se produjo una renovación de su historiografía. En 1972, Thomas Elsaesser propuso "rescatar" de la descalificación cultural al melodrama 
cinematográfico y en 1976, Peter Brooks publicó La imaginación melodramática que realizó una operación similar en la literatura europea donde destacó la importancia del desborde y el exceso que el modernismo dominante no había sabido contener. En América Latina, los ensayos de Jesús Martín Barbero (1993 [1987]) y Carlos Monsiváis (1988, 2000, 2002) catapultaron al melodrama que se contraponía, por esta vía, a otras formas de la modernidad que habían excluido a los sectores populares. De esta manera, la industria cultural - y con ella, la oralidad, el cuerpo y los sentimientos - fue contrapuesta a la moderna cultura letrada - concebida como escolar, censora y racionalista. La enorme circulación de las intervenciones de estos críticos consolidó esta mirada y, en cierta forma, clausuró la posibilidad de nuevas lecturas.

El presente artículo propone reabrir esas interpretaciones y formular algunas preguntas que, a nuestro entender, quedaron obturadas. Debido a la extensión que alcanzaron las hipótesis sobre el melodrama y el rol que las mismas tuvieron al momento de sentar las bases para una historia de los medios en América Latina, consideramos que se trata de una cuestión ineludible para nuestro campo de estudios. La elección de La ley que olvidaron no es azarosa. De la misma manera que el melodrama, la figura de González Castillo también fue "rescatada" a comienzos de la década de 1990 (FORD; MAZZIOTTI, 1991) a partir de la premisa de que su figura había sido largamente "olvidada". Su "rescate" permitía mostrar que los "verdaderos" gestos vanguardistas de las primeras décadas del siglo XX habían tenido lugar en el interior de la industria cultural, antes que en los ámbitos de la cultura letrada. La puesta en escena de Los invertidos en 1990, por parte del director y crítico Alberto Ure, fue presentada como un acontecimiento polémico, al que siguió la publicación de la obra por la editorial Puntosur, rodeada de un texto del propio Ure (1991) y otro de Aníbal Ford y Nora Mazziotti (1991). En 2011 la Biblioteca Militante de la Editorial de Razón y Revolución volvió a publicar Los invertidos y otras obras, mientras se sucedían las reseñas críticas sobre la obra de González Castillo en el teatro y en el cine.

En las páginas que siguen me detendré en algunos aspectos de La ley que olvidaron que han sido desatendidos por la crítica, al no considerar la producción cinematográfica como parte de una historia de los medios y la industria cultural. Para ello será necesario revisar el rol del melodrama en la puesta en discusión de temas relativos a las concepciones de familia, maternidad y matrimonio. Aunque no contamos con fuentes que nos permitan reconstruir con precisión qué rol ocupó el film en esos debates, resulta difícil 
eludir el modo en que introduce argumentos a favor de una ley de adopción que recién sería aprobada en 1948 pero que había sido tratada en el Congreso de la Nación en 1933 y 1938, sin alcanzar consenso entre distintos sectores políticos (VILLALTA, 2003).

Por otra parte, el film introduce una serie de ambigüedades que nos permite preguntarnos quiénes se verían beneficiados con la promulgación de esta ley tanto como para quién era necesario este film. Lejos de responder en forma simple a esas preguntas, $L a$ ley que olvidaron nos enfrenta a numerosas paradojas y nuestra conclusión es que la interpretación de este film como una ficción que respondía a intereses de los sectores populares - porque así lo hacía en términos generales el género melodramático o porque el guión guarda coherencia con el anarquismo profesado por su guionista - no parece sostenerse en un análisis pormenorizado.

El artículo está dividido en cuatro partes. En la primera, reconstruiremos el modo en que La ley que olvidaron presenta sus personajes y los ambientes donde transcurre la historia. Consideraremos especialmente en qué medida responde a las reglas del melodrama cinematográfico de ese período y en qué medida esas reglas podían servir a los fines del anarquismo. En segundo lugar, nos detendremos en una pregunta que se pone en escena: ¿en qué consiste una verdadera madre? Nos parece importante considerar por qué esa pregunta resultaba pertinente para el público y también por qué Libertad Lamarque era la actriz más apropiada para encarnar ese rol. En la tercera parte nos detendremos en la cuestión de la ley. El film pone en escena la tensión entre la maternidad concebida como una cuestión de la naturaleza o como algo adquirido y que puede ser objeto de legislación. También están presentes las tensiones entre ley y religión y el modo en que estas cuestiones adoptan rasgos diferentes, según se trate del pobre o del rico. En la cuarta parte, nos detendremos en una serie de films donde Libertad Lamarque vuelve a encarnar madres que se ven obligadas a enfrentar cambios del modelo de familia tradicional. Este recorrido nos permitirá verificar la reiteración del mismo mecanismo utilizado por La ley que olvidaron en 1937, a lo largo de varias décadas y contextos, para extraer algunas conclusiones.

\section{Melodrama y anarquía}

En La ley que olvidaron, la trama, los personajes y los conflictos parecen responder punto por punto a las exigencias del género. Una muchacha huérfana, bella, alegre y bondadosa trabaja como mucama en la casa de una viuda que se ve obligada a subalquilar 
los cuartos de una casa que supo conocer tiempos mejores. Todos maltratan a la bella sirvienta, con excepción de un joven estudiante del que ella está perdidamente enamorada. La niña de la casa queda embarazada de un novio que le promete casamiento pero no antes de finalizar sus estudios universitarios. Para ocultar la deshonra de su hija (y, por lo tanto, de ella misma) la viuda acude a una argucia poco original: aleja a la joven de Buenos Aires mientras dura el embarazo. Luego del parto, le entrega el bebé a María, la sirvienta huérfana. Desposeída de todo - inclusive de una reputación para perder - María recibe a la niña con amor y alegría, sin pensar en la deshonra que este acto le acarreará.

A pesar de tantas desgracias - o inclusive, debido a ellas - la pobre sirvienta brilla con brillo propio. Desde el inicio, el espectador reconoce en ella a Libertad Lamarque, la verdadera estrella del film que incluye un tango en honor del personaje que interpreta: Yo soy María de José González Castillo y Alfredo Malerba. El tango refuerza el nombre del personaje que remite, por supuesto, al de la Virgen María, a quien se alude también mediante múltiples referencias visuales. De la misma manera que la Virgen con el niño Jesús, María ofrece su amor y cuidado a la niña, sin condiciones. La pobre huérfana, con absoluta entrega y generosidad se convierte así en una madre virgen (COSSE, 2006).

Hasta aquí, la película no deja lugar a ambigüedades: los ricos son crueles e hipócritas, los pobres son buenos pero desafortunados. Los errores de los ricos tienen solución: el novio termina sus estudios y cumple con la promesa de casamiento para criar a la niña en familia. Pero la felicidad de la pareja, es la fatalidad de la muchacha pobre para quien la bebé es todo. Por eso, al enterarse del plan, María/Libertad Lamarque se transmuta en una leona y decide escapar con su cachorra. Como la animalización es recurrente en el film, la figura no es exagerada sino la consecuencia lógica de una idea de la maternidad compuesta por una cuota de deseo y de entrega irracionales. La paradoja es que el film recurre a la animalización, al mismo tiempo que argumenta que la maternidad no es un hecho biológico.

En la última parte, la historia da un giro. La madre biológica - siempre enfundada en trajes, sombreros y peinados sofisticados - recupera a la niña con ayuda de la policía. Acusada del secuestro de la criatura, María va a prisión pero el estudiante - ahora convertido en un abogado prestigioso - consigue salvarla. El joven - junto con el espectador - ha sido testigo del egoísmo, la hipocresía y la cobardía con que ha actuado la madre de sangre, así como de la bondad, empeño y amor incondicional con que María 
cuidó a la niña. El abogado la defiende con pasión en un juicio donde, frente a los argumentos de la fría ley puestos en boca del juez, prevalecen los argumentos del amor.

La niña, por su parte, grita y clama por María/Libertad Lamarque, mientras su madre biológica se maquilla la nariz mirándose a un espejito. Pero, como la ley es fundamental en esta historia, no faltará ni una cuota de justicia poética, ni una escena dramática adicional. La niña enferma y pasa varios días sin dormir hasta que María/Libertad Lamarque llega junto a su lecho a cantarle un arrorró. Como la escena forma parte de un film industrial, se trata de un arrorró que a esa altura de la historia se convirtió en un leitmotif y que ese año Libertad Lamarque grabaría como Nono, con letra de José González Castillo y música de Alfredo Malerba (segundo esposo de Libertad Lamarque en la vida real). La última escena muestra a María/Libertad Lamarque aprendiendo a leer junto a la niña. Los padres observan la escena con satisfacción mientras desde un auto lujoso, el joven abogado llama la atención de María que lo saluda feliz detrás de una ventana donde se dibujan las letras de la palabra FIN.

La película es tajante en la descripción de la decadencia moral, la hipocresía y la falta de escrúpulos de una burguesía porteña que vive de apariencias. Para la dueña de casa, viuda de un militar que no dejó ni un céntimo de herencia, el descenso social es una amenaza tangible. El historiador Matthew B. Karush observó respecto de La ley que olvidaron que "Ferreyra subraya la división de clase en la escena inicial" y añade:

[...] posicionar a Lamarque en el lado más bajo de la división de clase y, por lo tanto, en el lado moralmente superior, la convertía en objeto de identificación para el público. Como otras óperas tangueras, esta película está muy lejos de las historias de violentos compadritos o "milonguitas" condenadas a la prostitución, pero mantiene la filiación con el pobre y la condena del rico, propias del melodrama popular (KARUSH, 2013, p. 148).

Coincidimos con Karush en que, a fines de la década del treinta, la decadencia moral del rico se había convertido en un cliché del cine argentino pero nos preguntamos, en cambio, si la filiación con el pobre constituye el mensaje central del film. En el guión de González Castillo ese cliché se combina con algunos rasgos del anarquismo que, como señaló David Viñas, no desdeñó utilizar "ciertos recursos del melodrama larmoyante" (VIÑAS, 1983). De hecho, resulta notable que entre los rasgos que definen el "anarquismo latinoamericano", nos encontramos con numerosos tópicos de La ley que olvidaron: la crítica frontal a "las fachadas de los "barrios elegantes", la "frivolidad", la exhibición de "condecoraciones" que corroboran el "gasto inútil" y "un tieso acorazamiento". Viñas 
añade aún: "Se trata de la crítica de quienes viven derrochando lo que han heredado sin esfuerzo alguno. Herencia de la que saben su precio pero de la que desconocen sus valores y que sólo funciona en términos decorativos" (VIÑAS, 1983, p. 18). Por esta vía, el anarquismo como ideología de clase habría sido sustituido progresivamente por el anarquismo como redención personal y moral, una forma de conducta, más que un instrumento de la política de clase (VIÑAS, 1983, p. 23). Si esto es así, la cultura de masas sería un instrumento muy apropiado para llegar a los sectores obreros, algo que los historiadores del cine han señalado respecto de la filmografía de José Agustín Ferreyra (CUARTEROLO, 2009). En síntesis, a fines de la década de 1930 no resultaba sorprendente una película donde se enfrentaban ricos y pobres. La pregunta que se nos impone, en cambio, es por qué se había vuelto necesario explicar en qué consistía una "verdadera madre".

\section{Libertad Lamarque, una madre actriz}

En cualquier caso, no cabía duda de que el melodrama era la fórmula más adecuada para explicar la maternidad y que Libertad Lamarque - que a lo largo de su carrera participaría, entre otras, en La cigüeña dijo sí (1960), El pecado de una madre (1960), Los hijos que yo soñé (1964), El hijo pródigo (1968), La sonrisa de mamá (1972), Mamá (1975) y La mamá de la novia (1978) - era la mejor actriz para encarnar ese rol.

En La ley que olvidaron se presentan dos madres biológicas y ambas pertenecen a la burguesía: la viuda del militar, dueña de la casa donde transcurre una parte significativa del film y su hija, cuyo embarazo puede producir la deshonra. La vieja madre interpretada por la reconocida actriz Pepita Muñoz - es autoritaria y cascarrabias. No cesa de insultar a María y de marcar sus faltas pero no sabe poner ningún límite a su propia hija que es, en consecuencia, caprichosa y malcriada. Y, aunque pregona su autonomía, no es capaz de resolver sus propios problemas. Por eso reclama auxilio a su madre como una niña pequeña cuando se ve en apuros. La joven madre nunca se hace responsable de sus actos y culpa a los demás por haberla "forzado" a ocultar su maternidad.

Las madres burguesas se presentan, de esta forma, como seres irresponsables que pretenden sostener una imagen de severidad pero, en el fondo, son débiles e impotentes frente a los caprichos de los hijos que no saben educar. Sólo esconden sus errores para no quedar ellos mismos expuestos frente a la sociedad que los juzga, porque la apariencia es lo único que importa. Es una clase que sólo valora lo que no posee: es lo que ocurre con la 
muchacha cuyo "instinto maternal" recién aflora cuando cree perdida a la niña, pero en cuanto el juez le otorga la tenencia, le suelta la mano y la deja escapar por arreglar su maquillaje. "Mi mamá me da la mano" es la frase que aprenden a escribir en la escena final del film. Y la única madre que da la mano es María.

Porque María/Libertad Lamarque, por el contrario, es puro instinto y generosidad. Con un vago recuerdo infantil de su madre y una vida de penurias, ha podido construir un modelo de maternidad inquebrantable. Del recuerdo de su madre se destaca una belleza que ella ha heredado - realzada por vestidos admirables que, en cambio, le han sido arrebatados, lo cual deja flotando la idea de que tal vez su pobreza es consecuencia de su orfandad. En cualquier caso, el instinto de María es animal. De hecho, cuando está a punto de morir de inanición, da de comer lo poco que tiene a los animales. La madre biológica, en cambio, carece de todo instinto y cuando le regalan una perrita para llenar el hueco de la hija perdida, no puede sino rechazarla. La perra, en cambio, cuida sin dudar a sus cachorros. La película valora estas muestras de ternura que ubican a María - y con ella a los pobres - más cerca de la naturaleza que de la sociedad. Los ricos, en cambio, han borrado todo instinto bajo pátinas de una civilización de la que sólo ha quedado el maquillaje. Ese contraste se reproduce en la oposición ciudad/campo y Buenos AiresInterior del país, ya que el único personaje rescatable dentro del mundo de los patrones es el estudiante que puede contrapesar su clase social con un origen provinciano.

Entre los ricos, los varones alcanzan la madurez al recibirse en la Universidad y las mujeres al casarse. Sorprendentemente, ni una cosa ni la otra están vistas con buenos ojos. El médico y el abogado sólo pueden estar del lado de los buenos porque no utilizan ni las armas de la medicina ni las argucias de la ley, por el contrario, recetan "la medicina del cariño" y "la ley del amor". El casamiento, a su vez, adolece de todo afecto o romanticismo. La pareja de jóvenes aspira a casarse como un deber social pero el casamiento se demuestra innecesario en relación con un amor que ya han consumado. Durante la boda, una solterona acuerda casarse con un comerciante en una escena que carece de todo romanticismo, es el diálogo entre dos pícaros para los cuales el casamiento es un contrato, una negociación de cuidados a cambio de patrimonio personal.

En varias ocasiones, el film recurre al fundido de imágenes para representar el contraste entre ricos y pobres. Un balde de hielo para el champagne se transforma en un balde de agua sucia donde se escurre un trapo de piso; María se transfigura en su patrona frente al espejo, antes de volver a la realidad. El mismo mecanismo es utilizado para 
convertir la muñeca de María, único recuerdo de su infancia, en el bebé que recibe a su cuidado. El recurso permite mostrar la contraposición pero también la continuidad entre dos mundos. En el primer caso, el acento está puesto en el contraste: champán frente a mugre, superficialidad y ocio frente a trabajo y limpieza. En el segundo, la sirvienta que sueña con el ascenso social, forma parte del repertorio de clichés del melodrama, donde no hay ninguna condena a los patrones, sino el deseo de emularlos. El tercer caso es el que ofrece mayor interés: el deseo infantil se concreta con una alteración inexplicable: la muñeca se transforma en un bebé ajeno. En el film, los pobres ni siquiera tienen derecho a sus propios hijos, apenas les está permitido cuidar los de los ricos.

\section{La ley escrita}

La trama de La ley que olvidaron se propone como una historia realista y verosímil ya que aunque se guardaran en el mayor de los secretos, es muy probable que el público conociera historias similares. No resulta aventurado imaginar que abundaran los casos de hijas de la burguesía que ocultaban sus hijos como una carta robada: convivencia sin reconocimiento. De hecho, el prohijamiento fue una fórmula extendida en una época en que no existían leyes de adopción y dio lugar a un sinnúmero de variantes: padres que anotaban a los nietos como propios y bastardos criados por la familia (Cf. TORRADO, 2012). Madres-hermanas, abuelas-madres, alteraciones generacionales e ilegitimidades legitimadas que funcionaban como material en bruto para el melodrama.

Sin embargo, la película no se limita a describir una situación que el público conocía, sino que enjuicia, condena y le da forma escrita a un reclamo. Al terminar el juicio, se inserta la imagen de la tapa de un libro firmado por el Doctor Alberto Galindez: La Ley del corazón (La ley que olvidaron), de la editorial Luz, un detalle innecesario para la trama pero muy útil, en cambio, para hacer un guiño al espectador que conocía la editorial Claridad, un símbolo de los escritores nucleados alrededor del Grupo de Boedo. Desde 1928 González Castillo impartía clases en la Universidad Popular de Boedo y en 1932 fundó la peña Pacha Camac sobre la Avenida Boedo (KOSS, 2011).

Sin embargo, la justicia y la ley - que resultan omnipresentes en el film - sólo parecen servir a los poderosos. La policía acompaña al rico para quitarle la niña a María y encarcela a la protagonista injustamente. El tribunal no condena a la acusada por secuestro - delito que el público nunca supuso que había cometido - pero no le otorga la tenencia. El veredicto está redactado con una sintaxis rebuscada, mediante fórmulas del lenguaje escrito 
que se vuelven absurdas al pasar a la oralidad y vuelven la justicia opaca para el pobre. Sin embargo, las consecuencias de la sentencia son claras para María que por eso grita: "Usted se ha equivocado, es mía".

La sentencia que perjudica al pobre parece confirmar la interpretación de Karush que ve en la película una historia clasista. La escena, sin embargo, también provoca otro tipo de asociaciones: el tribunal semeja una Iglesia donde el altar ha sido reemplazado por el estrado del juez. El público se pone de pie y se sienta ritualmente ante las indicaciones del Juez que "va a dar lectura al veredicto" con la misma fórmula litúrgica de la "Lectura de los Santos Evangelios”. En este sentido, es útil recordar que hasta 1948 la adopción se encontraba bajo jurisdicción de la Iglesia que actuaba a través de Sociedades de Beneficencia (VILLALTA, 2003). En cualquier caso, cuando la sentencia no es favorable a María, Alberto le dice: "Hay otra justicia superior, confiemos en ella". Y por las dudas, agrega: "Yo siempre estaré a tu lado y Dios estará con nosotros". Como señalamos antes, el nombre de María trae la simbología cristiana a la historia, reforzada por el tango Yo soy María, que habla de una mujer que lleva en su "entraña la fuente de amor" aunque, paradójicamente, el tema es cantado por María que se presupone virgen, al menos hasta la última escena del film, que deja varias cuestiones abiertas.

En esa escena, María aprende a escribir junto a Pochita. El sobrenombre permite que quede en la ambigüedad quién ha tenido el privilegio de otorgarle un nombre y ratifica que se pactó un acuerdo entre los padres biológicos y la muchacha: ellos conservan la hija y permiten a María mantener contacto con la pequeña que continúa llamándola "mamita". María, que hasta entonces había demostrado ser una mujer responsable y trabajadora incansable, se muestra ahora completamente aniñada. Se encuentra en una posición subordinada frente al maestro y la niña que se atreve, incluso, a señalarle un error de ortografía. La película, que supuestamente ha defendido el punto de vista del pobre, señala finalmente su falta: el analfabetismo. Y disciplina al personaje mediante la escritura. No habría que olvidar que - en la película - La ley del corazón no es otra cosa que un libro escrito por un abogado. La controversial relación entre escritura y pasión es aún más evidente en otras obras de González Castillo. En la primera escena de Los invertidos el hijo del protagonista transcribe un informe sobre un asesinato cometido por un homosexual. La escritura le permite visibilizar la homosexualidad de su padre y anticipa el desenlace de la historia. La escritura arroja luz sobre la homosexualidad que, en la obra, está asociada al 
vampirismo y la noche. La obra introduce además una paradoja notable: la homosexualidad produce relaciones estériles pero podría ser hereditaria.

En el caso de La ley que olvidaron, estado civil y criminalidad femenina mantienen una relación directa. Cuando el joven abogado visita la cárcel, se enumeran los delitos cometidos por cada presa: una es infanticida y soltera, otra está acusada del asesinato de su marido y "afortunadamente" no tiene hijos, la tercera es una ladrona que no tiene hijos porque "son escasas las delincuentes madres". En la última celda se encuentra María que la carcelera presenta como un caso curioso que por querer ser madre, robó una criatura. Y agrega: "Es una muchacha humilde". ¿Por qué era necesario subrayar que se trataba de "una muchacha humilde" cuando todas las presas del film son pobres? Lo curioso no era una presa pobre sino que una mujer pobre robara un bebé. Pero el comentario permite mostrar que una mujer rica también podría robar un bebé para criar amorosamente un niño.

Durante el juicio, el alegato del fiscal subraya la pobreza de María como un agravante que obligaba a la menor a vivir "en la mayor pobreza" mientras "sus padres legítimos son personas pudientes y de figuración social". Sin embargo, el alegato del fiscal es ridiculizado y todos protestan en la sala porque consideran excesiva la condena. Lo notable, sin embargo, es que la película ve con buenos ojos los atenuantes del acto que llevó a cabo una joven huérfana y pobre con quien el público se identifica, cuando en verdad, se trata de un delito habitualmente cometido por mujeres ricas.

La película hace recaer sobre una muchacha rica la entrega de su bebé y sobre una muchacha pobre la maternidad adoptiva. Aunque resulta imposible medir cuántas personas aspiraban a adoptar un niño/a con anterioridad a la ley de 1948, las cifras de madres solteras son, en cambio, muy elocuentes: a principios de los años cuarenta, "el $80 \%$ de las madres solteras en Buenos Aires eran argentinas, de las cuales el 60\% provenía del interior, la mitad de ellas tenía menos de 21 años, el 42\% eran analfabetas, el 47\% tenía menos de cuatro años de escolarización, el 55\% eran empleadas domésticas y el 20\% eran trabajadoras industriales" (COSSE, 2006, p. 35). De manera que la madre soltera de la película se ubica en la minoría estadística, mientras que María es una fiel representante de los guarismos: provinciana, analfabeta y empleada doméstica.

El film no se limita a argumentar contra una condena injusta sino que la justicia como institución es cuestionada y ridiculizada. El argumento es que son las leyes del melodrama - es decir, del corazón - las que no toleran esa condena. La paradoja, sin embargo, es que por medio de la inversión de representatividades de los personajes 
involucrados en la historia, creemos estar defendiendo el punto de vista de la muchacha pobre cuando, en verdad, estamos aceptando el punto de vista de las madres de sectores medios y altos que deseaban una ley de adopción que les permitiera criar hijos de madres pobres como propios. La inversión de valoraciones queda expuesta en las palabras del abogado defensor cuando dice que la actitud de su defendida "lejos de constituir delito, denuncia en ella una elevación de sentimientos que no ha demostrado tener quien dio a luz a la menor puesto que la alejó del calor de su ternura y de la claridad de su espíritu, por egoístas o por equivocadas razones sociales". Y, por si quedara alguna duda, aclara: "la verdadera madre es quien le dio su amor, su protección moral, su vida", es decir, la madre adoptiva.

La ley que "rige la vida de las almas" y permitiría hacer verdadera justicia "no está escrita" argumenta el abogado. Pero es sabido que debería ser "La ley del corazón: esa es la ley que olvidaron y que solo Dios dicta en cada caso". Por supuesto, él se ocupará de escribirla. Mientras tanto, las palabras que utiliza durante la defensa son muy sugestivas: "Pido pues su absolución y pido también que en holocausto al cariño que siente por la niña, se le devuelva su tenencia". Entre las definiciones de "holocausto" figura "Un acto de abnegación total que se lleva a cabo por amor" (RAE), un sentido difícil de compatibilizar con el de "gran matanza de seres humanos" pero que coincide en la idea de sacrificio. Resulta sencillo concluir, en consecuencia, que las verdaderas madres son las que se sacrifican por los hijos. Por nuestra parte, no podemos dejar de apuntar que en Los invertidos, son los homosexuales quienes se inmolan sacrificialmente luego de matar al amante (FOSTER, 1989). Y el melodrama traduce los argumentos legales en los versos de una canción que canta Libertad Lamarque/María:

Es mía, solo mía, toda mía/ Es hija de una falta que tuvo esa mujer/ Y entonces como madre fue una indigna / Yo tengo más derecho / que solo por su vida /puse en juego mi honradez. /Yo la crié, yo la crié [...] No sabe la cunita en que durmió /cuánto sufrí cuando enfermó / Y me la quitan sabiendo de que nadie /puede darle más amor que yo (LA LEY QUE...1937).

\section{Secuelas}

En la década de 1930 la industria cinematográfica había conseguido formalizar los procesos de producción a través del studio system. Si bien la industria cinematográfica en Argentina no alcanzaba a competir con los grandes centros, producía una cantidad importante de films para el público local y competía por el mercado cinematográfico en algunas ciudades latinoamericanas como Montevideo, Lima o Bogotá. En ese contexto, 
con más de sesenta películas filmadas entre Argentina y México y una significativa discografía, el rostro y la voz de Libertad Lamarque eran inconfundibles para el mundo hispano donde se recortaba como una verdadera figura del star system. A diferencia de otro tipo de divas que basaron sus roles en la seducción o el carácter, Lamarque encarnó un prototipo maternal a lo largo de su prolífica carrera. Supo darle cuerpo a este prototipo de mujer ingenua, al punto de encarnar con éxito la paradoja de una madre virgen. ¿Por qué resultaba apropiada para esos roles?

En 1959, se produjo en México Mis padres se divorcian con una pareja estelar: Libertad Lamarque y Arturo de Córdova. Allí, Lamarque hace de ella misma: una cantante exitosa cuya carrera podría verse perjudicada por un romance. Por ese motivo, se casa en secreto, algo que parece excitante y romántico al comienzo pero luego el embarazo vuelve inviable vivir en la mentira. La protagonista abandona su carrera para formar una familia tradicional porque "cuando una mujer es madre ya no debe ser otra cosa", sentencia. Sin embargo, la nueva situación revela lo que siempre ha sido evidente y la protagonista no deseaba ver: se ha casado con un simpático vago y jugador empedernido que no es capaz de sostener el hogar. A diferencia de lo que ocurría en La ley que olvidaron, donde se reclamaba una legislación que reparara lo que se imponía de suyo (el amor maternal), en esta película, se muestran los efectos de la ley de divorcio que avanza sobre una moral y unas costumbres que no necesariamente han cambiado. La película deja caer sentencias del tipo "Cuando uno se casa es para siempre" y muestra que el trabajo femenino es aceptable siempre y cuando no se anteponga a la familia y la maternidad. Lo más interesante es el modo en que argumenta sobre la tenencia de la hija en favor del cónyuge con mayores recursos económicos. Aunque inicialmente el juez dicta la tutela compartida, lo que supone que la niña vivirá un mes con el padre y otro con la madre, la madre protesta y reclama que "la niña debe quedar conmigo" ya que "el padre carece de recursos" y "la privará de todo". Es notable que la madre no apele aquí a un argumento "maternal", no alude al lazo entre madre e hija sino a los recursos materiales que la favorecen.

De la misma forma que en La ley que olvidaron, la película elige un caso excepcional para la época. Se trata de un matrimonio que privilegió el trabajo de una mujer más exitosa que el marido en su carrera. La película incluye pasos de comedia sobre las deudas constantes del marido que es un pícaro seductor, irresponsable pero encantador e invierte la situación más habitual para la época donde la mujer que se dedicaba completamente a la familia, salía del matrimonio sin dinero ni posibilidad de mantener 
económicamente a sus hijos luego del divorcio. En otras palabras, el argumento que en el film favorece a la mujer, solía favorecer al marido en la vida real.

Sin embargo, el público también estaba al tanto de los sucesos familiares de Libertad Lamarque en la vida real. Justamente, el star system consistió en la elevación de figuras que ofrecían su vida al público, al punto de que los sucesos de la vida privada se confundan con la ficción. En ese sentido, era sabido que Lamarque se había casado muy joven, había tenido una hija y se había separado pero como no existía divorcio vincular en la Argentina, inicia un juicio por la tenencia de su hija que dura más de una década. De acuerdo con su autobiografía, durante todo ese período en el que ya había formado una nueva pareja con Alfredo Malerba - productor y autor de varios de los temas cantados por Lamarque - la actriz debe simular ante la prensa que vivía únicamente para su hija ya que estaba en juego la tenencia de la menor. Muchos años más tarde, Lamarque cuenta el secuestro de su propia hija que vivía con su padre en Uruguay (LAMARQUE, 1986). El relato - donde Lamarque no desconoce la ilegalidad del episodio que protagoniza subraya la inhabilidad moral de su ex marido pero, notablemente, también toma en consideración el modo en que sus dotes de actriz le facilitan el engaño para recuperar a su hija: “...Yo, disfrazada de 'pobre cosa', desfigurada por completo con un peinado que jamás había usado, sin maquillaje" le dice a la directora de la escuela de su hija que intuye su engaño: "No señora directora, ¿en qué puedo engañarla? - me quité los lentes para apoyar más mi sinceridad, ¡que me viera los ojos!... puse en ellos (como en cine cuando quiero hacerlo) franqueza, alegría y dulzura, apoyada por mi habitual sonrisa. ¿En qué puedo engañarla? - repetí." (LAMARQUE, 1986, p. 175).

La cita es notable porque no sólo le cuenta a su público el modo en que construyó sus personajes en el cine, sino en la vida real. En una situación límite - la recuperación de su hija - la actriz no desaparece sino que se potencia, como se potenció luego la construcción de su personaje de solitaria ante la prensa, mientras mantenía oculta su relación con Malerba. La escena subraya el modo en que Lamarque construye un personaje similar al que había actuado en La ley que olvidaron y para ello se disfraza de "pobre cosa", se presenta mal peinada y sin maquillaje, por oposición a la mala madre del film y a su propia condición de actriz exitosa que comenzaba a contar con buenos ingresos. El cierre de este episodio entrelaza maternidad, amor, legalidad y el secreto - tan caro al melodrama - como si fueran inescindibles:

Sólo así, con mi hija a mi lado, en Buenos Aires, pude iniciar la separación legal en Argentina y el divorcio en Montevideo, que fueron 
años y años de vivir siempre con el temor de que desde la otra orilla viniera alguien a robarme a mi hija, o que se descubriera el secreto de mi amor, que pusiera en tela de juicio mi buen nombre, impidiendo con eso a la justicia darme la tenencia de mi nena (LAMARQUE, 1986, p. 177).

La cita sobre su propia vida condensa las tensiones entre legalidad y legitimidad que Lamarque representó en el cine a lo largo de toda su carrera. Y apenas unas páginas más adelante brinda detalles sobre el incremento de su patrimonio a medida que avanzaba en su carrera, las propiedades que compró para toda su familia y, en particular, para su hija. De esta manera, aunque en el momento del secuestro de su hija en Uruguay, se coloca en el lugar de víctima, una estrella no puede perdurar en esa posición y por eso consigue finalmente hacer confluir maternidad y celebridad, amor y patrimonio.

En Mis padres se divorcian el abogado de la protagonista propone sobornar al marido para acelerar el acuerdo ya que, aunque la ley le va a dar la razón, va a ser un trámite lento, de manera que le conviene ofrecerle dinero para cerrar el caso cuanto antes. Es notable que en su Autobiografía, la idea del secuestro de la hija de Lamarque también es puesta en boca del abogado de la actriz con similares argumentos. En el film, la idea de cambiar a los hijos por dinero se muestra como un acto revulsivo que el padre rechaza con honor. Opta, en cambio, por ganarse a su hija con su simpatía. El film deja a la mujer doblemente acorralada ya que no debería aceptar dinero a cambio de sus hijos pero tampoco le está permitido ganárselos mediante la simpatía que se ve con humor en el caso del padre pero es censurada por la hija que no perdona a la madre cuando retoma la actuación y comienza a flirtear con otros hombres. Por eso, cuando finalmente el juez dicta la sentencia de divorcio, la protagonista vuelve con el único hombre posible para una mujer honesta: el padre de su hija. El film que, como vimos, tiene algunos puntos de contacto con la vida de Lamarque, no parece aconsejar, sin embargo, que el público imite su camino.

Un año después del estreno de Mis padres se divorcian, la misma pareja estelar protagoniza La cigüeña dijo sí (México, 1960). Se trata de una comedia de enredos donde una joven pareja quiere casarse y que se conozcan los respectivos padres, ambos viudos. Previsiblemente, el padre de la novia y la madre del novio también terminan casados. Todo parece marchar bien hasta que las dos parejas anuncian que van a tener un hijo. La comedia pone el foco en la diferencia generacional pero otorga protagonismo a la pareja adulta: lo que en la joven pareja es una noticia "natural" (la llegada del primer hijo), en la pareja mayor es completamente excepcional y permite desplegar todo su machismo al 
personaje interpretado por Arturo de Córdova: ¡no sólo va a ser padre antes que su yerno que también es su hijastro - sino que ha dejado embarazada a su madre! El guión está basado en una obra que el dramaturgo español Carlos Llopis había escrito en 1951, había sido filmado en Argentina por Enrique Carreras en 1955 y vuelto a filmar en 1971 por Palito Ortega con el título de La familia hippie. ¿Por qué resultaría tan atractiva esta comedia familiar a lo largo de dos décadas?

A comienzos de los años sesenta, cuando se estaba transformando la idea de juventud, la versión protagonizada por Libertad Lamarque y Arturo de Córdova muestra que quienes viven como jóvenes son, paradójicamente, los adultos. Los jóvenes actúan en forma tradicional (buscan trabajo estable, se casan, tienen hijos) y los adultos actúan como jóvenes (tienen sexo, nuevas parejas, nuevos hijos). En un sentido similar, Adolfo Bioy Casares publicó Diario de la guerra del cerdo en 1969 que Leopoldo Torre Nilsson llevó al cine en 1975. En la novela de Bioy Casares, los jóvenes - que son violentos e irracionales - declaran la guerra a los viejos - que son egoístas y lascivos. Sin embargo, aunque todo el relato sugiere que el adulto va a ser víctima de los jóvenes, concluye trágicamente con la muerte del hijo. Por el contrario, en las comedias familiares protagonizadas por Libertad Lamarque, el enfrentamiento generacional se resuelve con el nacimiento de muchos hijos aunque no puede pasar desapercibido que en todos los casos, son los adultos quienes "ganan" la batalla. Sin embargo, al comparar las dos versiones argentinas resulta notable el desplazamiento de foco desde la pareja de padres mayores en 1960 hacia el protagonismo de la pareja juvenil (especialmente Palito Ortega) en 1975.

Una conclusión inevitable de La familia hippie es que el resultado del cuestionamiento generacional es la confusión familiar. La madre - interpretada en este caso por Elina Colomer, que había representado por años la madre de La familia Falcón, la comedia familiar más célebre de la televisión argentina de los años sesenta - brinda "Por el hijo de los padres que será hermano de nuestros hijos". El padre - interpretado por el actor Ángel Magaña - brinda "Por el hijo de los hijos que será nieto de los padres y sobrino de los hermanos". Y, finalmente, Palito Ortega concluye "Y que tengamos que reunirnos pronto por el hijo de los amigos que será amigo de los nietos, los padres y los abuelos".

\section{Conclusiones}

El origen del melodrama es contemporáneo a la Revolución Francesa, de allí que las tensiones entre los contrastes sociales que ponía en escena y una legislación moderna 
pretendidamente universal, nunca lo abandonaron. En los melodramas que hemos analizado, las desigualdades sociales se presentan en forma invertida: la muchacha pobre de La ley que olvidaron es víctima de un problema que afectaba mayoritariamente a las jóvenes de clase alta. La mujer que reclama la tenencia de su hija en Mis padres se divorcian, actúa como habitualmente lo hacían los varones. Y los adultos de La cigüeña dijo sí, como los jóvenes... Este mecanismo de la industria cultural permite la identificación del público con personajes que se encuentran en una posición de debilidad (muchacha pobre, mujer divorciada, joven que recién se inicia en la vida adulta) y el desplazamiento de acciones que podrían resultar censurables (raptar una niña, sobornar a una ex pareja, competir con los hijos). Por ese motivo, merecería discutirse la calificación de "realista" de la cinematografía de José Agustín Ferreyra.

La pregunta inicial que me acercó a este film fue cómo era posible que un anarquista reclamara una ley. Las biografías de José González Castillo insisten en ejemplos que demostrarían que fue consecuente con su ideología. Nunca se casó con la madre de sus hijos e intentó inscribir uno de los niños con el nombre de Descanso Dominical pero como no se lo permitieron, lo llamó Catulo Ovidio (Catulo Castillo, poeta y autor de célebres letras de tango). Se trata de anécdotas que, sumadas al escándalo y la censura que sufrió Los invertidos, avalaron la interpretación de González Castillo como un "Anarquista, perseguido y exiliado" [...] Anarquista pietista y tolstoiano, amigo de chorros, prostitutas, vagabundos y curdas, conocedor de la vida de pobres y marginales..." (FORD; MAZZIOTTI, 1991, p. 77, 79). Como señala Carlos Rama, “Ese 'humildismo’ o 'pietismo' responde a la mejor tradición del pensamiento anarquista, vertiente ideológica que es la posición inicial de todo el grupo de Boedo" (RAMA, 1990: LIV). Si bien el "pietismo" tiende inicialmente a posiciones individualistas, en el siglo XIX adoptaría paulatinamente otra lógica según la cual era un deber del Estado crear un clima moral adecuado para que todos puedan obrar bien. De manera que si el anarquismo llegó a "utilizar" el Estado para alcanzar algunos de sus fines, resultaba aún menos problemático concebir un fin instrumental para la industria cultural. En este sentido, abundan las citas donde declara su intención de aprovechar el afecto que el público manifestaba por los medios de comunicación, a favor de sus propios intereses políticos (CUARTEROLO, 2009).

Sin embargo, esta interpretación de González Castillo como "anarquista tolstoiano" convierte a Los invertidos en una excepción dentro de la obra del autor ya que - a diferencia del resto de su obra - sus argumentos para explicar la homosexualidad no se 
habrían alejado del positivismo "cientificista" de su época (FORD; MAZZIOTTI, 1991, p. 79). En ese contexto, su interés por la ley es interpretado como una crítica a una situación injusta y por ese motivo llegó a incluir en El hijo de Agar un fragmento del Código Civil vigente en la época sobre "hijos adulterinos, incestuosos o sacrílegos" que "no tienen derecho a hacer investigaciones jurídicas sobre la paternidad o la maternidad".

El melodrama es el género del secreto por excelencia. Construye un sistema de velos, sombras, espejos e inversiones que permiten revelar algunas cuestiones que, de otra forma, resultan demasiado oscuras. Por ejemplo, si cualquiera contara cómo engañó a la directora del colegio de su hija con el fin de raptar a la niña, sólo veríamos un acto ilegal e ilegítimo. Sin embargo, cuando Libertad Lamarque cuenta este acto en su Autobiografía, lejos de producir escándalo, nos acerca la actriz al personaje ficcional con el que el público se identificó a lo largo de toda su carrera. La predilección por encarnar personajes que guardan semejanza con su vida real se mantuvo estable a lo largo de los años. En 1975 protagonizó la telenovela Mamá donde una vez más, encarnó el rol de gran diva y madre ejemplar. En lugar de socavar su legitimidad como actriz, la mentira confirma la eficacia del personaje ingenuo, simultáneamente virginal y maternal que actúa en los films y en la vida. Lamarque venía a confirmar que su actuación - que no fue necesariamente verosímil - fue eficaz para la vida real. De allí que llegar a saber que durante más de diez años se vio obligada a "engañar" a su público para engañar, en verdad, a los jueces que tenían en sus manos la tenencia de su hija, sólo viene a probar la injusticia de las leyes y la astucia de la actriz, jamás su falta de franqueza. El público ha sido formado en este sistema en el cual no es necesario que las estrellas sean verosímiles y mucho menos aún, sinceras.

Lo único importante es que actúen para el público la posición de debilidad con la que éste se identifica. Lo que resulta difícil de sostener es que la crítica ratifique e intensifique la veracidad de esa posición. Las operaciones de "rescate" del melodrama a las que asistimos desde la década del sesenta, así como las operaciones de "rescate" de figuras supuestamente marginales como González Castillo, reproducen un mecanismo similar por el cual la valoración del melodrama como "sirvienta pobre" de los géneros de la industria cultural desplaza el modo en que vehiculizó argumentos que poco beneficiaron a los más débiles.

Mencionamos el giro que introduce La ley que olvidaron en la última escena que sirve para mostrar que la escritura es indispensable para que la protagonista sea aceptada socialmente. ¿Podía un melodrama exaltar el cuerpo, la oralidad y las pasiones, al mismo 
tiempo que movilizaba al público en favor de una ideología y una ley? Entendemos que el objetivo de una Historia de los medios no tiene por qué fundarse en una valoración de géneros, autores y actores que conduzca a la conformación de un canon. Aunque definir los objetivos de esa Historia excede los alcances de este artículo, resulta un marco indispensable para interpretar el rol del melodrama a lo largo de esa Historia y los matices que adoptó en distintas etapas y contextos.

\section{Referencias}

BROOKS, Peter. The melodramatic imagination: Balzac, Henry James, melodrama and the mode of excess. New Haven: Yale University Press, 1995.

COSSE, Isabella. Estigmas de nacimiento. Peronismo y orden familiar 1946-1955. Buenos Aires: FCE-Universidad de San Andrés, 2006.

COUSELO, Jorge Miguel. El negro Ferreyra: un cine por instinto. Buenos Aires: Freeland, 1969.

COUSELO, Jorge Miguel y otros. Historia del cine argentino. Buenos Aires: CEAL, 1993.

CUARTEROLO, Andrea. Los antecedentes del cine político y social en la Argentina (1896-1933). En: LUSNICH, Ana Laura; PIEDRAS, Pablo. Una historia del cine político y social en Argentina (1896-1969). Buenos Aires: Nueva librería, 2009. p. 145-172.

DI NÚBILA, Domingo. La época de oro. Buenos Aires: del Jilguero, 1998.

ELSAESSER, Thomas. Tales of sound and fury: observations on the family melodrama. In: Monogram. Volumen 4, Amsterdam School for Cultural Analysis, 1972, p. 2-15.

FORD, Aníbal; MAZZIOTTI, Nora. José González Castillo: cine mudo, fábricas y garconieres. En: González Castillo, José. Los invertidos. Buenos Aires: Puntosur, 1991. p. 77-92.

FOSTER, David William. José González Castillo's Los invertidos and the Vampire Theory of Homosexuality. En: Latin American Theatre Review, 22/2, 1989.

KARUSH, Matthew B. Cultura de clase. Radio y cine en la creación de una Argentina dividida (1920-1946). Buenos Aires: Ariel, 2013.

KOSS, Natacha. Las innovaciones teatrales de José González Castillo. En: Revista del Centro Cultural de la Cooperación, $\mathrm{n}^{\circ}$ 12, mayo/agosto 2011. Disponible en: https://www.centrocultural.coop/revista/12/las-innovaciones-teatrales-de-jose-gonzalezcastillo. Consultado el 6 abr. 2019.

LA LEY QUE OLVIDARON. Dirección: José Agustín Ferreyra. Intérpretes: Libertad Lamarque, Santiago Arrieta, Herminia Franco, Pepita Muñoz et al. Guión: José González 
Castillo. Buenos Aires: Sociedad Impresora de Discos Electrofónicos (SIDE), 1937. Filme (77 minutos), son., blanco y negro.

LAMARQUE, Libertad. Autobiografía. Buenos Aires: Javier Vergara, 1986.

LUSNICH, Ana Laura; PIEDRAS, Pablo. Una historia del cine político y social en Argentina (1896-1969). Buenos Aires: Nueva librería, 2009.

MARTÍN-BARBERO, Jesús. Communication, culture and hegemony: from the media to mediations. London: Sage, 1993 [1987].

MONSIVÁIS, Carlos. Escenas de pudor y liviandad. México: Grijalbo, 1988.

MONSIVÁIS, Carlos. South of the border, down Mexic's way. El cine latinoamericano y Hollywood. En: Aires de familia: cultura y sociedad en América Latina. Barcelona: Anagrama, 2000. p. 29-41.

MONSIVÁIS, Carlos. El melodrama: "No te vayas, mi amor, que es inmoral llorar a solas". En: HERLINGHAUS, Hermann (ed.). Narraciones anacrónicas de la modernidad: melodrama e intermedialidad en América Latina. Santiago de Chile: Editorial Cuarto Propio, 2002. p. 105-124.

RAMA, Carlos. El anarquismo en América Latina. Caracas: Fundación Biblioteca Ayacucho, 1990.

TORRADO, Susana. Historia de la familia en la Argentina moderna (1870-2000). Buenos Aires: Ediciones de la Flor, 2012.

URE, Alberto. 1991. La realidad del escenario. Notas sobre la puesta en escena de Los invertidos. En: GONZÁLEZ CASTILLO, José. Los invertidos. Buenos Aires: Puntosur, 1991, p. 65-75.

VILLALTA, Carla. Entre la ilegitimidad y el abandono: la primera ley de adopción de niños. En: Cuadernos del Sur. Historia. Bahía Blanca, Argentina, n 32, p. 27-48, 2003.

VIÑAS, David. Anarquistas en América Latina. México: Editorial Katún, 1983.

Submetido em: 29.04.2019

Aprovado em: 22.05.2019 